\title{
Brief, biochemical perspective of Virus, Lipids, Apoptosis and Ageing
}

\author{
Dr Ikam Anthony Igbojekwe \\ MRSB, Geriatrics Clinician and Medical Lipid Biochemist, Professor of Life Science \\ DOI: 10.29322/IJSRP.12.01.2022.p12157 \\ http://dx.doi.org/10.29322/IJSRP.12.01.2022.p12157
}

\begin{abstract}
The aim of this search was not to put forward the unknown but to have an insight into the known for the advancement of life science. The hypothetical and theoretical approach of this paper is to keep alert the imminent danger virus as a spontaneous chemical assembly can pose to human which equally is chemically constituted. The approach is in relation to lipids both in virus and human. This is extremely necessary before the moving object crashes. There is need for scientist to have more focus to viral entry into living cells as it concerns interaction with lipids. Viral presence in living cells will definitely affect life functions, hence early aging and reduced life span.
\end{abstract}

Index Terms- biochemical, virus, lipids, apoptosis, ageing.

\section{INTRODUCTION}

$\mathrm{M}$ an is an organized chemistry (made up of solid, liquid, and gases), liable to chemical reaction and metabolism. The process of information storage in genes are all chemistry. The last universal ancestor (Luca)), had not been able to explain the origin of man. In virus the link between metabolism and genes is broken. Vision is not virus as virus is a process The life founder's molecule RNA is primarily liable to assault. Clearly, being dead is different from not being alive. Rarely dead is associated with early total destruction of all organic molecules in an individual. Death releases DNA carrying information out into the environment where it may persist for a while and there is statistical probability that it may transform into new and/ or another DNA/RNA variant. VIRUS, LIPIDS, AND HUMANS.

Eukaryotes, human inclusive, are known to possess lipid bolster in their cellular and subcellular compartment(semi permeable membrane).

Billions of viruses abound in the ecosystem which forms the pool of viruses that surround the intracellular environment of humans. The virus may be non pathogenic and/or pathogenic in association with human cells, tissues and organs. Viral entry is preceded by weak ionic interaction between the vision and cell surface glycosaaminoglycans(heparan and chondrointin sulphate) There is promotion of adhesion. Virus surf along cell surface until internalization of receptor occur(glycosphingolipids and anionic phospholipids). It is assumed glycosphingolipids carry Morty that makes HIV recognized by mature sensitive cells. Component of lipid raft including glycolipids, sphingomyelin, glycophosphatidylinositol,anchored proteins, and transmembrane proteins. Lipid rafts forms an important cluster at which the viral lipids interact during entry by enveloped and non enveloped viruses. The virus on entry into host cell block thenormal enzymatic actions of living host. Consequently, the enzyme are channeled into the viral genomic replication. Life is a four letter word (DNA nitogeneous bases). Increasing disorder is loss of information and increasing order is gain in information.

\section{APOPTOSIS}

This is the programmed (regulated), cell death which starts uteri. It is normal and facilitates the arrangement of organs and tissues during embryonic and fetal period. The hypothetical concern of the effect of viral lipids on deranged apoptosis is not out of place. Non pathotogetnic viral particles may under probability interfere with normal apoptotic process and and become pathogenic obeying hesinberg's projection concerning subatomic particles. In essence the deranged apoptosis may quicken normal aging process and reduce the life span of an individual. In this process the signalling of protein synthesis as concerns tumor necrosis factor superfamily member 6 and formation of death inducing signalling complex (DISC) which bind to Logan's is disrupted.

On earth viruses kill more living things than any other predator. They shape the balance of species in the ecosystem ranging from those of open ocean to that of human bowel. They spur evolution during natural selection and allowing the swapping of genes. Interference of enzymatic actions by viral entry into living tissues increases the risk of human diseases. Associates of aging (Biological, social, physiological, behavourial, environmental, are affected. Metagenomics hard contributed immensely in getting the range of life in ecological setting. Malfunctioning immune system, DNA oxidation, disrupted epigenic maintenance such as DNA methylation as a result of viral lipid facilitation of virus host interaction. There is wide range of cellular and molecular damage. This lead to gradual decline in physical and mental capacity. A growing risk of disease and untimely death.

Organisms that divide by fission do not age except infected by virus. Procreation may be affected by the interaction between virus and human host lipid bilayer as there is link between viral lipids and human genome. There is the tendency that the body defence mechanism which attack viral lipids may equally affect the nucleic acid phosphatesugar polyester backbone since lipids are also Ester although with different functional group. This can destroy the genome.

Dangerous mutation may exterminate the human race. Unless there is reduced utilization of boogie viral lipids and human and human host interaction may likely alter the human genome 
back to Prebiotic era as climatic change supervenes. However anywhere there is large crude oil deposit there is bound to be billions of viral particles. It is left for scientist to determine the effect of viral particles on the neurons of human species in that ecosystem. Temperate and tropical climate determines the pathogenicity in terms of non pathogenic ones. There is likelihood that lipid enveloped viruses can derive better in temperate climate and vice versa.

\section{CONCLUSION}

Normal aging and life span is under threat especially among the developing world. However other pathogenic agents and factors contribute to the ugly trend but the viral impact had not been put into serious check.Climatic change may bring about the evolution of very dangerous strain of virus that can end human life on earth.

\section{REFERENCES}

[1] (a)Economist August 222020

[2] (b)Search in scientific medicine Dr Ikam Anthony Igbojekwe MRSB uk july 2021

[3] (c) Human evolutionary biology 1994by Arndt von hippel.

[4] (d)Akiro Ono 2020

[5] (e) Leventel. ET. al Simon andsampoid

\section{AUTHORS}

First Author - Dr Ikam Anthony Igbojekwe MRSB, Geriatrics Clinician and Medical Lipid Biochemist, Professor of Life Science 